\title{
Activated charcoal: a highly efficient promoter for selective oxidation of alcohols to aldehydes and ketones by $\mathrm{K}_{2} \mathrm{~S}_{2} \mathrm{O}_{8}$ at solvent-free conditions
}

\author{
Akbar Safari and Behzad Zeynizadeh*
}

Department of Chemistry, Faculty of Science, Urmia University, Urmia 5756151818, Iran

\begin{tabular}{l}
\hline C H R O N I C L E \\
\hline Article history: \\
Received January 21, 2015 \\
Received in revised form \\
March 29, 2015 \\
Accepted 9 April 2015 \\
Available online \\
9 April 2015 \\
\hline Keywords: \\
Activated charcoal \\
Aldehydes \\
Ketones \\
$\mathrm{K}_{2} \mathrm{~S}_{2} \mathrm{O}_{8}$, Oxidation
\end{tabular}

\begin{tabular}{l} 
A B S T R A C T \\
\hline Selective oxidation of primary and secondary alcohols to the corresponding aldehydes and \\
ketones was achieved efficiently using $\mathrm{K}_{2} \mathrm{~S}_{2} \mathrm{O}_{8} /$ activated charcoal system. All reactions were \\
carried out at solvent-free conditions $\left(40-45^{\circ} \mathrm{C}\right)$ within $15-60$ min to give the products in high \\
to excellent yields.
\end{tabular}
to excellent yields.

\section{Introduction}

The selective oxidation of primary and secondary alcohols to the corresponding aldehydes and ketones is an important and pivotal reaction in organic synthesis ${ }^{1-4}$. Pyridinium chlorochromate ${ }^{5}$, $\mathrm{Pr}_{4} \mathrm{NRuO}_{4}{ }^{6}, \mathrm{BaMnO}_{4}{ }^{7,8}, \mathrm{KMnO}_{4} / \mathrm{kieselguhr}^{9}, \mathrm{MnO}_{2}{ }^{10-12}, \mathrm{MnO} / \mathrm{kieselguhr}^{13}, \mathrm{DMSO} / \mathrm{CO}_{2} \mathrm{Cl}_{2}{ }^{14}$, $\mathrm{DMSO} / \mathrm{DCC}^{15}, \mathrm{DMSO} \cdot \mathrm{SO}_{3} \cdot \mathrm{Pyr}^{16}, \mathrm{Ag}_{2} \mathrm{CO}_{3} / \mathrm{celite}^{17,18}$, Dess-Martin periodinate ${ }^{19}, o$-iodobenzoic acid (IBX) ${ }^{20,21}, \mathrm{I}_{2} / \mathrm{Li}_{2} \mathrm{CO}_{3} /[\mathrm{bmim}] \mathrm{BF}_{4}{ }^{22}, \mathrm{TsNBr}_{2}{ }^{23}, \mathrm{CeO}_{2} / \mathrm{RuCl}_{3} \cdot \mathrm{H}_{2} \mathrm{O}^{24}, \mathrm{H}_{2} \mathrm{O}_{2} /$ hexamolybdochromate(III) ${ }^{25}$, air/ruthenium cluster ${ }^{26}$, air/copper-bisisoquinoline ${ }^{27}$, air/ruthenium/TEMPO ${ }^{28}$, and polymer-bound Co-oxidants in the presence of TEMPO catalyst ${ }^{29}$ are some of the oxidants which have been utilized for such transformation. However, most of the mentioned protocols suffer from several drawbacks in terms of harsh reaction conditions, use of expensive volatile organic solvents, high cost, instability, high toxicity and operational difficulty.

Recently, persulfate $\left(\mathrm{S}_{2} \mathrm{O}_{8}{ }^{2-}\right)$ as an alternative oxidant has achieved increasing attention in the oxidation of environmental contaminants ${ }^{30-40}$. Use of persulfate has several advantages. It is a strong * Corresponding author.

E-mail address: bzeynizadeh@gmail.com (B. Zeynizadeh) 
oxidizing agent and stable at room temperature. Heat, transition metal ions and UV radiation can excite persulfate to sulfate anion-radical $\left(\mathrm{SO}_{4}{ }^{-\bullet}\right)$ and this species significantly enhances the oxidation potential of persulfate ${ }^{41-43}$. In spite of this potentiality, the capability of persulfate for oxidation of alcohols is low. Therefore, such transformation with persulfate was rarely documented. The literature review shows that selective oxidation of alcohols to carbonyl compounds has been achieved by $\mathrm{K}_{2} \mathrm{~S}_{2} \mathrm{O}_{8}$ in a Brönsted ionic liquid ([Hmim] $\left.-\mathrm{CH}_{3} \mathrm{SO}_{3}\right)^{44}$. Though the method produces aldehydes and ketones selectively in moderate to high yields, however, using expensive ionic liquid as a solvent puts some restrictions to use this protocol for any practical applications.

In line of the outlined strategies and our ongoing attention to explore the synthetic applications of persulfate, herein, we wish to introduce activated charcoal as a highly efficient promoter for selective and efficient oxidation of primary and secondary alcohols to the corresponding aldehydes and ketones with $\mathrm{K}_{2} \mathrm{~S}_{2} \mathrm{O}_{8}$ at solvent-free conditions (Scheme 1).

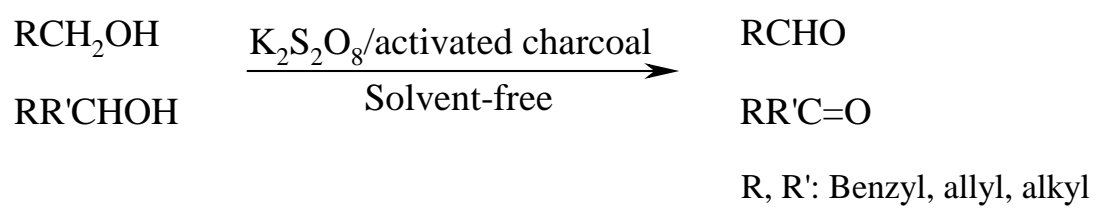

Scheme 1. Selective oxidation of alcohols by $\mathrm{K}_{2} \mathrm{~S}_{2} \mathrm{O}_{8}$ /activated charcoal system

\section{Results and Discussion}

Activated charcoal possesses quite a few unique characteristics. High degree and tunable micro porosity (just one gram of activated charcoal has a surface area of 500-1500 $\mathrm{m}^{2}$ ), high stability in caustic and acidic media and rich surface chemistry (due to ability to form surface-oxygen complexes) make this material very valuable as a promoter or solid bed for immobilization of other reagents ${ }^{45}$. Recently, we reported some useful applications of activated charcoal in organic synthesis ${ }^{46-48 .}$

Unique characteristics of activated charcoal and our goal to introduce a green and practical protocol for oxidation of alcohols by persulfate encouraged us to enhance the oxidative potential of $\mathrm{K}_{2} \mathrm{~S}_{2} \mathrm{O}_{8}$ by its incorporation with high surface area and micro porosity of activated charcoal. We also interested to perform the reactions at solvent-free conditions. Since, solvent-free reactions are desirable from ecological point of view and in many cases offer considerable synthetic advantages in terms of yield, selectivity and simplicity of the reaction procedures.

The influence of micro porose activated charcoal was studied by performing the solvent-free oxidation of benzyl alcohol with $\mathrm{K}_{2} \mathrm{~S}_{2} \mathrm{O}_{8}$ (Table 1). The results showed that oxidation of benzyl alcohol with the alone $\mathrm{K}_{2} \mathrm{~S}_{2} \mathrm{O}_{8}$ did not have a proper efficiency at room or elevated temperature (Table 1, entries 1 and 2) (Scheme 2, path a). By addition a small amount of micro porose activated charcoal to the mixture of $\mathrm{PhCH}_{2} \mathrm{OH}$ and $\mathrm{K}_{2} \mathrm{~S}_{2} \mathrm{O}_{8}$, the rate of oxidation reaction was dramatically accelerated and benzaldehyde was obtained as the sole product. More examinations revealed that the complete oxidation of benzyl alcohol into benzaldehyde required a molar equivalent of $\mathrm{PhCH}_{2} \mathrm{OH}: \mathrm{K}_{2} \mathrm{~S}_{2} \mathrm{O}_{8}(1: 3)$ and activated charcoal $(0.05 \mathrm{~g})$ at solvent-free conditions $\left(45-50{ }^{\circ} \mathrm{C}\right)$ (Table 1 , entry 5) (Scheme 2, path b). Although, using the excess amounts of $\mathrm{K}_{2} \mathrm{~S}_{2} \mathrm{O}_{8}(4 \mathrm{mmol})$ (entry 6$)$ or activated charcoal (0.1 g) (entry 9) per $1 \mathrm{mmol}$ of benzyl alcohol accelerated progress of the reaction, however, their results in decreasing the reaction time were not remarkable. So, the conditions mentioned in entry 5 were selected as the optimal. 


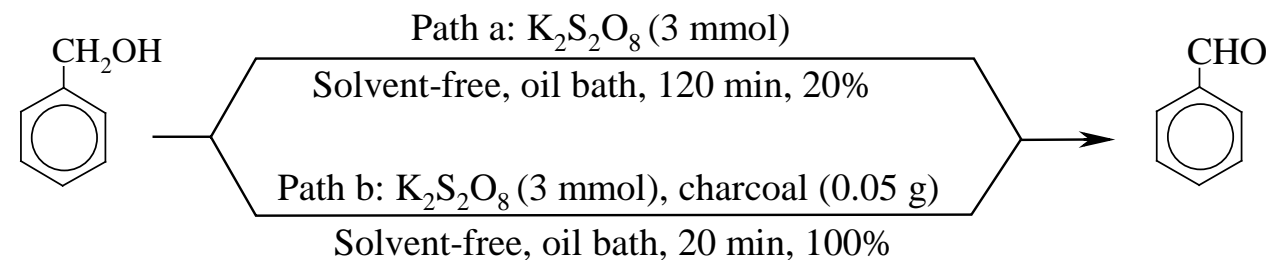

Scheme 2. Selective oxidation of benzyl alcohol by $\mathrm{K}_{2} \mathrm{~S}_{2} \mathrm{O}_{8}$ in the absence (path a) and presence of activated charcoal (Path b)

The studies also showed that $\mathrm{K}_{2} \mathrm{~S}_{2} \mathrm{O}_{8}$ /activated charcoal system has two distinguished characteristics: i) prolonging the reaction time ( $240 \mathrm{~min}$ ) and using the excess amounts of $\mathrm{K}_{2} \mathrm{~S}_{2} \mathrm{O}_{8}$ (4 mmol) did not carry out the over oxidation of benzaldehyde into benzoic acid (Table 1, entry 7), and ii) $\left(\mathrm{NH}_{4}\right)_{2} \mathrm{~S}_{2} \mathrm{O}_{8}$ as $\mathrm{K}_{2} \mathrm{~S}_{2} \mathrm{O}_{8}$ exhibited the same reactivity and selectivity in oxidation of benzyl alcohol to benzaldehyde (Table 1, entry 10). This means that changing the counter ion of persulfate did not affect the behavior of oxidation reaction.

Table 1. Optimization experiments for selective oxidation of benzyl alcohol to benzaldehyde by $\mathrm{K}_{2} \mathrm{~S}_{2} \mathrm{O}$ /activated charcoal system. ${ }^{\mathrm{a}}$

\begin{tabular}{cccccccc}
\hline Entry & $\begin{array}{c}\text { Charcoal } \\
(\mathrm{g})\end{array}$ & $\begin{array}{c}\mathrm{K}_{2} \mathrm{~S}_{2} \mathrm{O}_{8} \\
(\mathrm{mmol})\end{array}$ & Condition $^{\mathrm{b}}$ & $\begin{array}{c}\text { Time } \\
(\mathrm{min})\end{array}$ & $\begin{array}{c}\mathrm{PhCHO} \\
(\%)\end{array}$ & $\begin{array}{c}\mathrm{PhCH}_{2} \mathrm{OH} \\
(\%)\end{array}$ & $\begin{array}{c}\mathrm{PhCO}_{2} \mathrm{H} \\
(\%)\end{array}$ \\
\hline 1 & - & 3 & rt & 120 & - & - & - \\
\hline 2 & - & 3 & oil bath & 120 & 20 & 80 & - \\
\hline 3 & 0.05 & 1 & oil bath & 120 & 45 & 55 & - \\
4 & 0.05 & 2 & oil bath & 120 & 70 & 30 & - \\
5 & 0.05 & 3 & oil bath & 20 & 100 & - & - \\
6 & 0.05 & 4 & oil bath & 17 & 100 & - & - \\
\hline 7 & 0.05 & 4 & oil bath & 240 & 100 & - & - \\
\hline 8 & 0.1 & 2 & oil bath & 120 & 75 & 25 & - \\
\hline 9 & 0.1 & 3 & oil bath & 18 & 100 & - & - \\
$10^{\mathrm{d}}$ & 0.05 & 3 & oil bath & 20 & 100 & - & - \\
\hline
\end{tabular}

${ }^{\mathrm{a}}$ All reactions were carried out with $1 \mathrm{mmol}$ of benzyl alcohol at solvent-free conditions. ${ }^{\mathrm{b}}$ Temperature of oil bath was $45-50{ }^{\circ} \mathrm{C}$. ${ }^{\mathrm{c}} \mathrm{The}$ reaction was completed within $17 \mathrm{~min}$, however, prolonging the reaction time ( $240 \mathrm{~min}$ ) did not produce benzoic acid as an over oxidation product. ${ }^{\mathrm{d}}$ The reaction was carried out by $\left(\mathrm{NH}_{4}\right)_{2} \mathrm{~S}_{2} \mathrm{O}_{8}$.

The selectivity and oxidative potential of $\mathrm{K}_{2} \mathrm{~S}_{2} \mathrm{O}_{8} /$ activated charcoal system was further studied by examination of a broad range of primary and secondary alcohols at the optimized reaction conditions. Table 2 shows that structurally different benzylic, heteroaryl, allylic and aliphatic primary alcohols were efficiently and selectively oxidized to the corresponding aldehydes using 3 molar equivalents of $\mathrm{K}_{2} \mathrm{~S}_{2} \mathrm{O}_{8}$ and $0.05 \mathrm{~g}$ activated charcoal at solvent-free conditions $\left(40-45^{\circ} \mathrm{C}\right)$. All reactions were completed during 15-60 min without any over oxidation to produce carboxylic acid compounds. Investigation of the results reveals that electron donating substituents on aromatic rings generally activated benzylic alcohols leading to accelerate progress of the reaction, whereas, electron withdrawing groups prolonged the reaction time through the deactivation of benzylic alcohols. We also found that during the oxidation reaction with $\mathrm{K}_{2} \mathrm{~S}_{2} \mathrm{O}_{8}$ /activated charcoal system, the $\mathrm{C}=\mathrm{C}$ moiety was remained intact. So, geraniol as an allylic primary alcohol was successfully converted to the corresponding $\alpha, \beta$-unsaturated aldehyde (citral) without any side product formation (Table 2, entry 16). 
Table 2. Oxidation of primary alcohols to aldehydes by $\mathrm{K}_{2} \mathrm{~S}_{2} \mathrm{O}_{8} /$ activated charcoal system. ${ }^{\mathrm{a}, \mathrm{b}}$

\begin{tabular}{|c|c|c|c|c|}
\hline Entry & Substrate & Product & Time (min) & Yield (\%) \\
\hline 1 & & & 20 & 95 \\
\hline 2 & & & 55 & 98 \\
\hline 3 & & & 60 & 98 \\
\hline 4 & & & 50 & 96 \\
\hline 5 & & & 18 & 97 \\
\hline 6 & & & 20 & 98 \\
\hline 7 & & & 15 & 95 \\
\hline 8 & & & 35 & 94 \\
\hline 9 & & & 60 & 96 \\
\hline 10 & & & 55 & 98 \\
\hline 11 & & & 60 & 96 \\
\hline 12 & & & 40 & 94 \\
\hline 13 & & & 30 & 92 \\
\hline 14 & & & 50 & 85 \\
\hline 15 & & & 60 & 93 \\
\hline 16 & & & 45 & 90 \\
\hline 17 & & & 50 & 88 \\
\hline
\end{tabular}

${ }^{\mathrm{a}} \mathrm{All}$ reactions were carried out with the molar ratio of substrate $/ \mathrm{K}_{2} \mathrm{~S}_{2} \mathrm{O}_{8}(1: 3)$ in the presence of activated charcoal $(0.05 \mathrm{~g})$ at solvent-free conditions $\left(45-50^{\circ} \mathrm{C}\right)^{\mathrm{b}} \mathrm{All}$ starting materials were completely converted to the corresponding products. ${ }^{\mathrm{c}}$ Yields refer to isolated pure products. 
The summarized results in Table 3 show that the oxidation of various aliphatic and benzylic secondary alcohols with $\mathrm{K}_{2} \mathrm{~S}_{2} \mathrm{O}_{8}$ /activated charcoal system was also accessible. As it's seen, using 3 molar equivalents of $\mathrm{K}_{2} \mathrm{~S}_{2} \mathrm{O}_{8}$ and $0.05 \mathrm{~g}$ activated charcoal at solvent-free conditions $\left(40-45^{\circ} \mathrm{C}\right.$ ) efficiently oxidized secondary alcohols to the corresponding ketones. All reactions were completed within 20-55 min to afford the products in 92-98\% yields. In the case of secondary allylic alcohols, the oxidation of $\beta$-ionol with $\mathrm{K}_{2} \mathrm{~S}_{2} \mathrm{O}_{8}$ /activated charcoal system was also carried out selectively without the further oxidation of double bond (Table 3, entry 6). In addition, the successful conversion of (-)borneol to camphore (entry 7), shows that the present protocol can be used easily for the oxidation of more hindered secondary alcohols.

Table 3. Oxidation of secondary alcohols to ketones by $\mathrm{K}_{2} \mathrm{~S}_{2} \mathrm{O}_{8} /$ activated charcoal system. ${ }^{\mathrm{a}, \mathrm{b}}$

Entry

${ }^{a}$ All reactions were carried out with the molar ratio of Subs./ $\mathrm{K}_{2} \mathrm{~S}_{2} \mathrm{O}_{8}(1: 3)$ in the presence of activated charcoal (0.05 g) at solvent-free conditions $\left(45-50{ }^{\circ} \mathrm{C}\right) .{ }^{\mathrm{b}} \mathrm{All}$ starting materials were completely converted to the corresponding products. ${ }^{\mathrm{c}}$ Yields refer to isolated pure products.

The influence of activated charcoal on reactivity of $\mathrm{K}_{2} \mathrm{~S}_{2} \mathrm{O}_{3}$ is not clear, however, we think that high surface area and micro porosity of activated charcoal maybe play roles through a widespread interaction of $\mathrm{K}_{2} \mathrm{~S}_{2} \mathrm{O}_{8}$ with the alcohol, and excitation of persulfate to more powerful sulfate anion-radical $\left(\mathrm{SO}_{4}{ }^{-\bullet}\right)$ that accelerates the oxidation process.

\section{Conclusions}

In this investigation, we have shown that activated charcoal dramatically promotes the oxidative potential of $\mathrm{K}_{2} \mathrm{~S}_{2} \mathrm{O}_{8}$ towards alcohols. $\mathrm{K}_{2} \mathrm{~S}_{2} \mathrm{O}_{8}$ /activated charcoal system exclusively oxidizes various primary alcohols to the corresponding aldehydes and secondary alcohols to the ketones. All reactions were carried out at solvent-free conditions $\left(40-45^{\circ} \mathrm{C}\right)(15-60 \mathrm{~min})$ to afford the products in high to excellent yields. Versatility of this synthetic method for a broad range of alcohols, perfect selectivity and high efficiency as well as the benefits of solvent-free conditions are the advantages which make this protocol a useful addition to the present methodologies. 


\section{Experimental}

\subsection{General}

All reagents and substrates were purchased from commercial sources with the best quality and they were used without further purification. Activated charcoal was obtained from Merck Company (Art No 102186). ${ }^{1} \mathrm{H}(300 \mathrm{MHz})$ and ${ }^{13} \mathrm{C}(75 \mathrm{MHz}) \mathrm{NMR}$ spectra (in $\mathrm{CDCl}_{3}$, Aldrich 99.8\%) were recorded on $300 \mathrm{MHz}$ Bruker Avance spectrometer. All chemical shifts were measured with reference to TMS $(\delta=0.00 \mathrm{ppm})$. FT-IR spectra were recorded on Thermo Nicolet Nexus 670 spectrophotometer using the $\mathrm{KBr}$ pressed pellet technique. All products are known and were characterized by their ${ }^{1} \mathrm{H},{ }^{13} \mathrm{C}$ NMR and FT-IR spectra followed by a comparison with authentic samples ${ }^{49,50}$.

4.2 A typical procedure for selective oxidation of 4-chlorobenzyl alcohol to 4-chlorobenzaldehyde by $\mathrm{K}_{2} \mathrm{~S}_{2} \mathrm{O}$ /activated charcoal system

A mixture of 4-chlorobenzyl alcohol (0.143 g, $1 \mathrm{mmol}), \mathrm{K}_{2} \mathrm{~S}_{2} \mathrm{O}_{8}(0.810 \mathrm{~g}, 3 \mathrm{mmol})$ and activated charcoal $(0.05 \mathrm{~g})$ was ground in a mortar for $55 \mathrm{~min}$ at $45-50{ }^{\circ} \mathrm{C}$. The progress of the reaction was monitored by TLC ( $n$-hexane/EtOAc: 8/2). After completion of the reaction, the mixture was washed with EtOAc $(6 \mathrm{~mL})$ and then filtered. Evaporation of the solvent affords pure 4-chlorobenzaldehyde in $98 \%$ yield ( $0.138 \mathrm{~g}$, Table 2, entry 2$)$.

\section{Acknowledgments}

The financial support of this work was gratefully acknowledged by the Research Council of Urmia University.

\section{References}

1. Bäckvall J. -E. (2010) Modern Oxidation Methods, 2nd Ed, Wiley-VCH, Weinheim.

2. Tojo G., and Fernandez M. (2006) Oxidation of Alcohols to Aldehydes and Ketones, Springer, New York.

3. Sheldon R. A., and Kochi, J. K. (1981) Metal-Catalyzed Oxidations of Organic Compounds, Academic Press, New York.

4. Hudlicky M. (1990) Oxidations in Organic Chemistry, American Chemical Society, Washington, DC.

5. Corey E. J., and Suggs J. W. (1975) Pyridinium chlorochromate. An efficient reagent for oxidation of primary and secondary alcohols to carbonyl compounds. Tetrahedron Lett., 16, 2647-2650.

6. Ley S. V., Norman J., Griffith W. P., and Marsden S. P. (1994) Tetrapropylammonium perruthenate, $\mathrm{Pr}_{4} \mathrm{~N}^{+} \mathrm{RuO}_{4}{ }_{4}^{-}$, TPAP: a catalytic oxidant for organic synthesis. Synthesis, 639-666.

7. Fatiadi A. J. (1987) The classical permanganate ion: still a novel oxidant in organic chemistry. Synthesis, 85-127.

8. Firouzabadi H., and Mostafavipoor Z. (1983) Barium manganate. A versatile oxidant in organic synthesis. Bull. Chem. Soc. Jpn., 56, 914-917.

9. Lou J. -D., Wang M., Zhu L. -Y., and Fang Z. -G. (2003) Solvent free oxidation of alcohols catalyzed by $\mathrm{KMnO}_{4}$ adsorbed on Kieselguhr. Catal. Commun., 4, 647-649.

10. Fatiadi A. J. (1976) Active manganese dioxide oxidation in organic chemistry - Part I. Synthesis, 65-104.

11. Fatiadi A. J. (1976) Active manganese dioxide oxidation in organic chemistry - Part II. Synthesis, 133-167.

12. Taylor R. J. K., Reid M., Foot, J., and Raw S. A. (2005) Tandem oxidation processes using manganese dioxide: discovery, applications, and current studies. Acc. Chem. Res., 38, 851-869. 
13. Lou J. -D., Ge J., Zou X. -N., Zhang C., Wang Q., and Ma Y. -C. (2011) Effective oxidation of alcohols with manganes dioxide supported on kieselguhr under heterogeneous conditions. Oxidat. Commun., 34, 361-365.

14. Mancuso A. J., Huang S. -L., and Swern D. (1978) Oxidation of long-chain and related alcohols to carbonyls by dimethyl sulfoxide activated by oxalyl chloride. J. Org. Chem., 43, 2480-2482.

15. Pfitzner K. E., and Moffatt J. G. (1963) A new and selective oxidation of alcohols. J. Am. Chem. Soc., 85, 3027-3028.

16. Parikh J. R., and Doering W. V. E. (1967) Sulfur trioxide in the oxidation of alcohols by dimethyl sulfoxide. J. Am. Chem. Soc., 89, 5505-5507.

17. Mckillop A., and Young D. W. (1979) Organic synthesis using supported reagents - part I. Synthesis, 401-422.

18. Fétizon M. (2009) Silver(I) carbonate on celite. In: Paquette L. A., Crich D., Fuchs P. L., and Molander G. A. (Eds) Encyclopedia of Reagents for Organic Synthesis, 2nd Ed, Wiley, Chichester.

19. Dess D. B., and Martin J. C. (1983) Readily accessible 12-I-5 oxidant for the conversion of primary and secondary alcohols to aldehydes and ketones. J. Org. Chem., 48, 4155-4156.

20. Frigerio M., and Santagostino M. (1994) A mild oxidizing reagent for alcohols and 1,2-diols: $O_{-}$ iodoxybenzoic acid (IBX) in DMSO. Tetrahedron Lett., 35, 8019-8022.

21. More J. D., and Finney N. S. (2002) A Simple and Advantageous Protocol for the Oxidation of Alcohols with o-Iodoxybenzoic Acid (IBX). Org. Lett., 4, 3001-3003.

22. Lee S. B., and Lee J. C. (2009) Oxidation of benzylic alcohols with iodine and lithium carbonate in ionic liquid. Bull. Korean Chem. Soc., 30, 3107-3108.

23. Saikia I., Chakraborty P., and Phukan P. (2009) A new metal-free protocol for oxidation of alcohols using $N, N$-dibromo-p-toluenesulfonamide. Arkivoc, xiii, 281-286.

24. Vocanson F., Guo Y. P., Namy J. L., and Kagan H. B. (1998) Dioxygen oxidation of alcohols and aldehydes over a cerium dioxide-ruthenium system. Synth. Commun., 28, 2577-2582.

25. Mardur S. P., and Gokavi G. S. (2010) Selective oxidation of alcohols to aldehydes by hydrogen peroxide using hexamolybdochromate(III) as catalyst. J. Iran. Chem. Soc., 7, 441-446.

26. Kondo T., Kimura Y., Kanda T., Takagi D., Wada K., and Toshimitsu A. (2011) Simple and practical aerobic oxidation of alcohols catalyzed by a ( $\mu$-oxo)tetraruthenium cluster. Green Sustain. Chem., 1, 149-154.

27. Shen H. -Y., Ying L. -Y., Jiang H. -L., and Judeh Z. M. A. (2007) Efficient copper-bisisoquinoline-based catalysts for selective aerobic oxidation of alcohols to aldehydes and ketones. Int. J. Mol. Sci., 8, 505-512.

28. Dijksman A., Marino-Gonzalez A., i Payeras A. M., Arends I. W. C. E., and Sheldon R. A. (2001) Efficient and selective aerobic oxidation of alcohols into aldehydes and ketones using ruthenium / TEMPO as the catalytic system. J. Am. Chem. Soc., 123, 6826-6833.

29. Kloth K., Brunjes M., Kunst E., Joge T., Gallier F., Adibekian A., and Kirschning A. (2005) Practical TEMPO-mediated oxidation of alcohols using different polymer-bound Co-oxidants. Adv. Synth. Catal., 347, 1423-1434.

30. Huang K. C., Couttenye R. A., and Hoag G. E. (2002) Kinetics of heat-assisted persulfate oxidation of methyl tert-butyl ether (MTBE). Chemosphere, 49, 413-420.

31. Liang C. J., Bruell C. J., Marley M. C., and Sperry K. L. (2003) Thermally activated persulfate oxidation of trichloroethylene (TCE) and 1,1,1-trichloroethane in aqueous systems and soil slurries. Soil Sediment. Contam., 12, 207-228.

32. Anipsitakis G. P., and Dionysiou D. D. (2004) Radical generation by the interaction of transition metals with common oxidants. Environ. Sci. Technol., 38, 3705-3712.

33. Anipsitakis G. P., and Dionysiou D. D. (2004) Transition metal/UV-based advanced oxidation technologies for water decontamination. Appl. Catal. B: Environ., 54, 155-163.

34. Liang C., Bruell C. J., Marley M. C., and Sperry K. L. (2004) Persulfate oxidation for in situ remediation of TCE: I. activated by ferrous ion with and without a persulfate-thiosulfate redox couple. Chemosphere, 55, 1213-1223. 
35. Liang C., Bruell C. J., Marley M. C., and Sperry K. L. (2004) Persulfate oxidation for in situ remediation: II. activated by chelated ferrous ion. Chemosphere, 55, 1225-1233.

36. Huang K. C., Zhao Z., Hoag G. E., Dahmani A., and Block P. A. (2005) Degradation of volatile organic compounds with thermally activated persulfate oxidation. Chemosphere, 61, 551-560.

37. Liang C., Wang Z. S., and Bruell C. J. (2007) Influence of pH on persulfate oxidation of TCE at ambient temperatures. Chemosphere, 66, 106-113.

38. Waldemer R. H., Tratnyek P. G., Johnson R. L., and Nurmi J. T. (2007) Oxidation of chlorinated ethenes by heat-activated persulfate: kinetics and products. Environ. Sci. Technol., 41, 1010-1015.

39. Rastogi A., Al-Abed S. R., and Dionysiou D. D. (2009) Sulfate radical-based ferrousperoxymonosulfate oxidative system for PCBs degradation in aqueous and sediment systems. Appl. Catal. B: Environ., 85, 171-179.

40. Rastogi A., Al-Abed S. R., and Dionysiou D. D. (2009) Effect of inorganic, synthetic and naturally occurring chelating agents on Fe(II) mediated advanced oxidation of chlorophenols. Water Res., 43, 684-694.

41. Kolthoff I. M., Medalia A. I., and Raaen H. P. (1951) The reaction between ferrous iron and peroxides. IV. Reaction with potassium persulfate. J. Am. Chem. Soc., 73, 1733-1739.

42. House D. A. (1962) Kinetics and mechanism of oxidations by peroxydisulfate. Chem. Rev., 62, 185-200.

43. Oh S. -Y., Kim H. -W., Park, J. -M., Park H. -S., and Yoon C. (2009) Oxidation of polyvinyl alcohol by persulfate activated with heat, $\mathrm{Fe}^{2+}$ and zero-valent iron. J. Hazard. Mater., 168, 346-351.

44. Chaskar A. C., Bhandari, S. R., Patil A. B., Sharma O. P., and Mayeker S. (2009) Solvent-free oxidation of alcohols with potassium persulphate in the presence of Brönsted acidic ionic liquids. Synth. Commun., 39, 366-370.

45. Marsh, H., and Rodríguez-Reinoso F. (2006) Activated Carbon, Elsevier, Amsterdam.

46. Zeynizadeh B., and Setamdideh D. (2006) $\mathrm{NaBH}_{4} /$ charcoal: a new synthetic method for mild and convenient reduction of nitroarenes. Synth. Commun., 36, 2699-2704.

47. Setamdideh D., and Zeynizadeh B. (2006) Mild and convenient method for reduction of carbonyl compounds with the $\mathrm{NaBH}_{4} /$ charcoal system in wet THF. Z. Naturforsch., 61b, 1275-1281.

48. Dilmaghani K. A., Zeynizadeh B., and Parsajam H. (2012) The efficient synthesis of 3,4-dihydropyrimidin-2-(1H)-ones and their sulfur derivatives with $\mathrm{H}_{2} \mathrm{SO}_{4}$ immobilized on activated charcoal. Phosphorus, Sulfur, and Silicon, 187, 544-553.

49. Spectral database for organic compounds SDBS, http://sdbs.db.aist.go.jp/sdbs/cgibin/cre_index.cgi (accessed on Jan 2015).

50. NIST chemistry webbook, http://webbook.nist.gov/chemistry (accessed on Jan 2015). 